\title{
Avaliação de prestação de serviços ecossistêmicos em sistemas agroflorestais através de indicadores ambientais
}

\author{
Assessmentof ecosystem services provision in agroforestry systems through \\ environmental indicators
}
Évaluation de laprestation de services ecossistêmicos en systèmes agroflorestaux via dês indicateurs environnementaux

\author{
Evaluación de la prestación de servicios ecosistémicos en sistemas \\ agroforestales mediante indicadores ambientales
}

\author{
Renan Coelho de Vasconcellos ${ }^{1}$ \\ Norma Ely Santos Beltrão ${ }^{2}$ \\ Recebido em 11/02/2017; revisado e aprovado em 24/05/2017; aceito em 04/06/2017 \\ DOI: http://dx.doi.org/10.20435/inter.v19i1.1494
}

\begin{abstract}
Resumo: Este estudo tem como objetivo avaliar, de forma qualitativa, a prestação de serviços ecossistêmicos (SE) por tipo de sistemas agroflorestais (SAF) a partir de uma base de sete indicadores ambientais préselecionados. Os modelos de SAFs avaliados foram os multiestratificados, em aleias, taungya e cercas-vivas. Os SAFs multiestratificados possuem maior potencial de prestação de SE por possuírem composição que mais se assemelha a uma floresta natural.
\end{abstract}

Palavras-chave: sistemas agroflorestais; indicadores de sustentabilidade; carbono; nutrientes.

Abstract: The objective of this study is to evaluate qualitatively the ecosystem services (ES) by type of agroforestry systems (AFS) based on seven pre-selected environmental indicators. The models of AFSs evaluated were multi-stratified, in alleles, taungya and hedgerows. The multi-stratified AFS shave a greater potential for ES provision because they have the composition that most resembles a natural forest.

Keywords: agroforestry systems; sustainability indicators; carbon; nutrients.

Resumé: Cette étude vise à évaluer qualitativement la fourniture de services écosystémiques (SE) par type de systèmes agroforestiers (SAF) d'une base de sept indicateurs environnementaux pré-sélectionnés. Les modèles ont été évalués multistrates SAF dans les ruelles, taungya et haies. Les SAF pluristratifié sont un plus grand potentiel de fournir SE ayant l'adhésion qui ressemble à une forêt naturelle.

Mots-clés: systèmes agroforestiers; indicateurs de durabilité; le carbone; les nutriments.

Resumen: Este estúdio tiene como objetivo evaluar cualitativamente la prestación de servicios de los ecosistemas (SE) por tipo de sistemas agroforestales (SAF) de una base de siete indicadores ambientales preseleccionados. Los modelos fueron evaluados Multistrata SAF sen callejones, taungya y setos. Los SAFs Multistrata tienen mayor potencial para proporcionar SE por tener membresía que se asemeja a un bosque natural.

Palabras clave: sistemas agroforestales; indicadores de sostenibilidad; carbono; nutrientes.

\section{INTRODUÇÃO}

As pressões por uma atividade agrícola mais sustentável crescem em todas as regiões do planeta. O embate é polarizado entre aqueles que mantêm práticas convencionais e os que buscam iniciativas e mudanças conservacionistas, reduzindo as externalidades negativas provocadas pelas atividades de produção de alimentos (FERRAZ, 2003; PALUDO; COSTABEBER, 2012). Uma

\footnotetext{
$\overline{1}$ Instituto Federal do Pará, Breves, Pará, Brasil.

${ }^{2}$ Universidade do Estado do Pará (UEPA), Belém, Pará, Brasil.
} 
das formas de responder a esses interesses aparentemente conflitantes é a adoção de sistemas agroflorestais (SAFs).

Uma das primeiras conceituações de SAFs foi apresentada por Nair (1993), em que estes são descritos como sistemas de uso da terra em que ocorrem o uso de plantas lenhosas perenes junto com agricultura e/ou pecuária, em uma interação econômico-ecológica de seus componentes através de um arranjo espacial ou temporal. O grande atrativo dos SAFs em termos ambientais é a inclusão de espécies arbóreas junto com a atividade agropecuária.

Diversos autores, como Woda (2009) e Arco-Verde e Amaro (2015), apontam, como principais benefícios das árvores, a possibilidade de exploração madeireira controlada, produção de alimentos e produtos não madeireiros, aumento da viabilidade da produção, aumento da biodiversidade, tanto florística como faunística, produção de combustíveis e medicamentos, proteção contra erosões eólicas e hídricas, e ciclagem de nutrientes e matéria orgânica (MO) no solo.

Os SAFs tentam recriar condições presentes nos ambientes naturais, promovendo a oferta dos principais serviços ecossistêmicos (SEs) presentes em sistemas não antropizados. Tomando por base essas definições, tem-se que SEs são os aspectos dos ecossistemas utilizados (ativa ou passivamente) para produzir bem-estar humano. De modo mais aprofundado, ao definir SE, oS pontos-chave são: i) devem ser fenômenos ecológicos e ii) que eles não têm que ser diretamente utilizados. Dessa forma, percebe-se a dificuldade em mensurá-los pelo fato de eles não poderem ser cambiáveis dentro da economia e, na maioria dos casos, não podem ser extraídos ou separados da natureza. Os quatro tipos de serviços ecossistêmicos propostos pelo Millennium Ecosystem Assessment (MEA, 2005) - suporte, regulação, provisão e cultural - são elencados em diversos trabalhos que avaliam SAFs nessas condições. Desse modo, funções ou processos se tornam serviços se houver seres humanos que deles se beneficiem, conforme melhor exemplificado na Figura 1 (FISHER; TURNER; MORLING, 2009).

Dada a multifuncionalidade dos SAFs, Idol, Haggar e Cox (2011) apontam o crescente interesse do ramo científico nas duas últimas décadas em SAFs de pequenos agricultores localizados nos trópicos, em virtude de sua baixa renda, pressões socioeconômicas nos países em que vivem e por serem um dos primeiros a serem afetados pelas mudanças climáticas. 


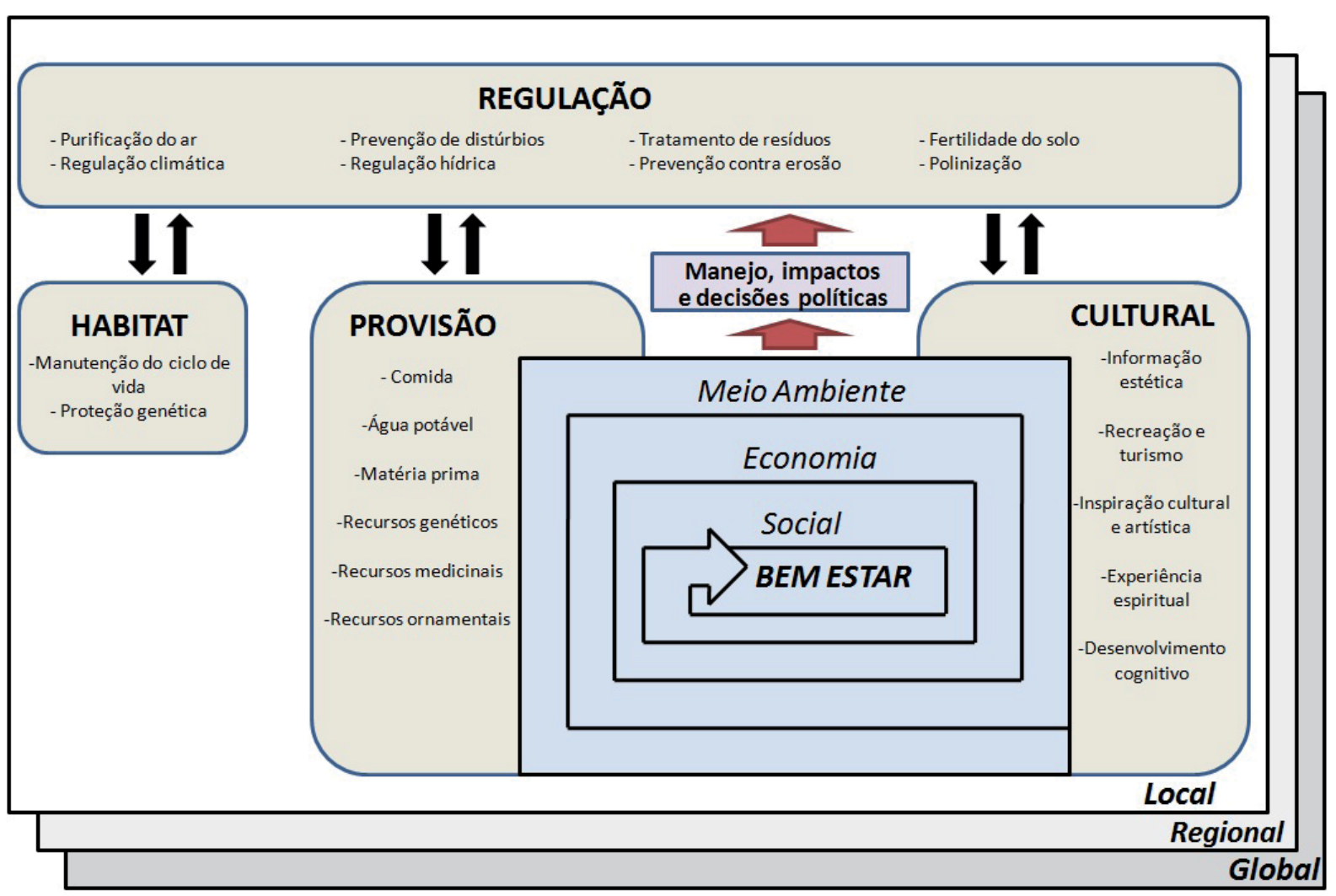

Figura 1- Modelo teórico conceitual da prestação de serviços ecossistêmicos

Fonte: Autores (2016).

Devido à complexidade das inter-relações dos fatores biofísicos em um ambiente, a prestação de SEs em um SAF pode ser afetada pelo modelo implementado. Dentre os diversos modelos de SAFs apresentados por Nair (1993), os mais utilizados no Brasil, segundo Torres et al. (2014), Torres (2015) e Velasques, Jacobi e Cardoso (2015), são os sistemas taungya, em aleias, multiestratos e cercas vivas. Ainda segundo esses autores, o modelo taungya é classificado como sequencial, no qual o uso do componente agrícola nos primeiros anos ( 2 a 4 ) serve para diminuir os custos da implantação do componente arbóreo de foco comercial. Após essa fase inicial, as espécies arbóreas formam uma floresta para aproveitamento econômico.

O modelo em aleias é definido por Torres (2015, p. 8) como um sistema "simultâneo que consiste na associação de culturas agrícolas intercaladas com árvores e/ou arbustos, geralmente fixadores de nitrogênio". Sistemas agroflorestais multiestrato, por sua vez, são aqueles que mais se aproximam de um ambiente natural, com maior permanência das espécies arbóreas e aproveitando as diferentes intensidades de radiação, umidade e sombreamento provocados pela diferença de estratos verticais (FROUFE; SEOANE, 2011). Por fim, no sistema de cercas vivas, também chamadas de quebra vento, as espécies arbóreas são usadas em fileiras externas, normalmente nos limites das propriedades ou das culturas agrícolas como forma de protegê-las dos ventos dominantes (VELASQUES; JACOBI; CARDOSO, 2015).

Nessa linha de raciocínio, este estudo se propõe a avaliar, de forma qualitativa e a partir de uma base de indicadores ambientais pré-selecionados, a prestação de serviços ecossistêmicos por tipos de sistemas agroflorestais usualmente adotados em florestais tropicais, mais especificamente na Amazônia. 


\section{MATERIAIS E MÉTODOS}

Para alcance do objetivo deste estudo, buscou-se uma abordagem teórica dos principais indicadores utilizados para mensurar determinados serviços ecossistêmicos oferecidos pelos SAFs. Trata-se, portanto, de uma pesquisa basicamente exploratória, especialmente por tratar-se de um tema pouco abordado na literatura e de significativa relevância para sistemas implantados em regiões tropicais como a Amazônia Brasileira. Além disso, esta pesquisa também tem alcance correlacional (SAMPIERI; COLLADO; LUCIO, 2014), pois pretende-se conhecer a relação ou grau de associação existente entre os indicadores de SEs e os principais desenhos de SAFs, especialmente taungya, aleias, multiestratos e cercas vivas.

Nesta pesquisa, a seleção dos indicadores foi realizada a partir de uma revisão bibliográfica sistemática que, segundo Flick (2009), tem foco direcionado para documentos de pesquisa selecionados a partir de critérios específicos. Dessa forma, foram levantados conceitos, definições e teorias relacionadas aos indicadores apropriados para mensurar a oferta de SEs. Conforme os tipos de indicadores ambientais em agroecossistemas apresentados por Ferraz (2003), foram selecionados indicadores gerais de diagnóstico que representam o estado geral do sistema e que respondem aos sinais de sua degradação.

\section{INDICADORES AMBIENTAIS EM SISTEMAS AGROFLORESTAIS}

Deponti, Eckert e Azambuja (2002) definem indicadores estratégicos como sendo aqueles que apresentam abrangência e profundidade suficientes para avaliar a sustentabilidade do sistema em questão. Dessa forma, procurou-se selecionar indicadores ambientais capazes de expressar os serviços ecossistêmicos fundamentais oriundos de SAFs na relação planta-solo-água-atmosfera.

Contudo, enquanto alguns indicadores apresentam valores estipulados em normas (a exemplo da sedimentação em corpos hídricos), outros, como a quantidade de nutrientes e carbono total no solo, incremento de biomassa aérea vegetal, evapotranspiração e biodiversidade, adquirem valores diferentes dependendo da finalidade desejada ou demais fatores bióticos em sinergia com esses serviços. Um mesmo solo, por exemplo, pode ser considerado fértil para certas culturas e impróprio para outras, assim como uma taxa de evapotranspiração pode ser grande para áreas de Cerrado, mas insuficiente no bioma amazônico.

Portanto, a partir dos quatro tipos de SE propostos por The Economics of Ecosystems and Biodiversity (TEEB FOUNDATIONS, 2010), e da verificação da presença e relevância de indicadores selecionados nos vários estudos consultados, tem-se um conjunto de indicadores que podem estar contemplados num SAF, sendo eles: i)serviço de provisão através da estimativa de biomassa arbórea para fins de exploração madeireira; ii) serviço de regulação através da manutenção da fertilidade do solo, regulações climática e hídrica e controle erosivo; iii) de habitat com a proteção genética pelo incremento de biodiversidade; e iv) cultural através do desenvolvimento cognitivo pelo conhecimento tradicional a respeito do uso de plantas medicinais. Um resumo dos indicadores, para serviços ecossistêmicos em SAFs e suas metodologias, se encontra na Tabela 1 a seguir.

O uso de SAFs é indicado por autores como Alves et al. (2011), devido à possibilidade de serem equiparáveis a áreas naturais de vegetação e como redutores de estoques de carbono microbiano. Outros benefícios são percebidos também na melhoria das propriedades físico-químicas da atividade microbiana no solo. 
A decisão a respeito da escolha da serrapilheira, como indicador frente às análises laboratoriais das propriedades físico-químicas de um solo, é justificada pelo menor custo entre as duas, mesmo que ambas tenham coletas amostrais de fatores similares - a camada superficial do solo e a matéria vegetal acumulada.

A presença de serrapilheira serve de indicativo de que há alguma autociclagem de nutrientes e matéria orgânica no ambiente, fator primordial para solos nas regiões tropicais, reconhecidos pela sua baixa fertilidade, mas com elevada capacidade de fixação de nutrientes com presença de vegetação (SOARES; FROUFE, 2015). Em sistemas agroflorestais, reconhecidos por tentarem recriar condições similares às de florestas naturais, a presença de bons valores de matéria orgânica em sua serrapilheira garante a não necessidade de adubação, evitando custos e danos de médio e longo prazo ao solo.

Tabela 1 - Serviços ecossistêmicos potencialmente encontrados em sistemas agroflorestais e procedimentos metodológicos por indicador de serviços.

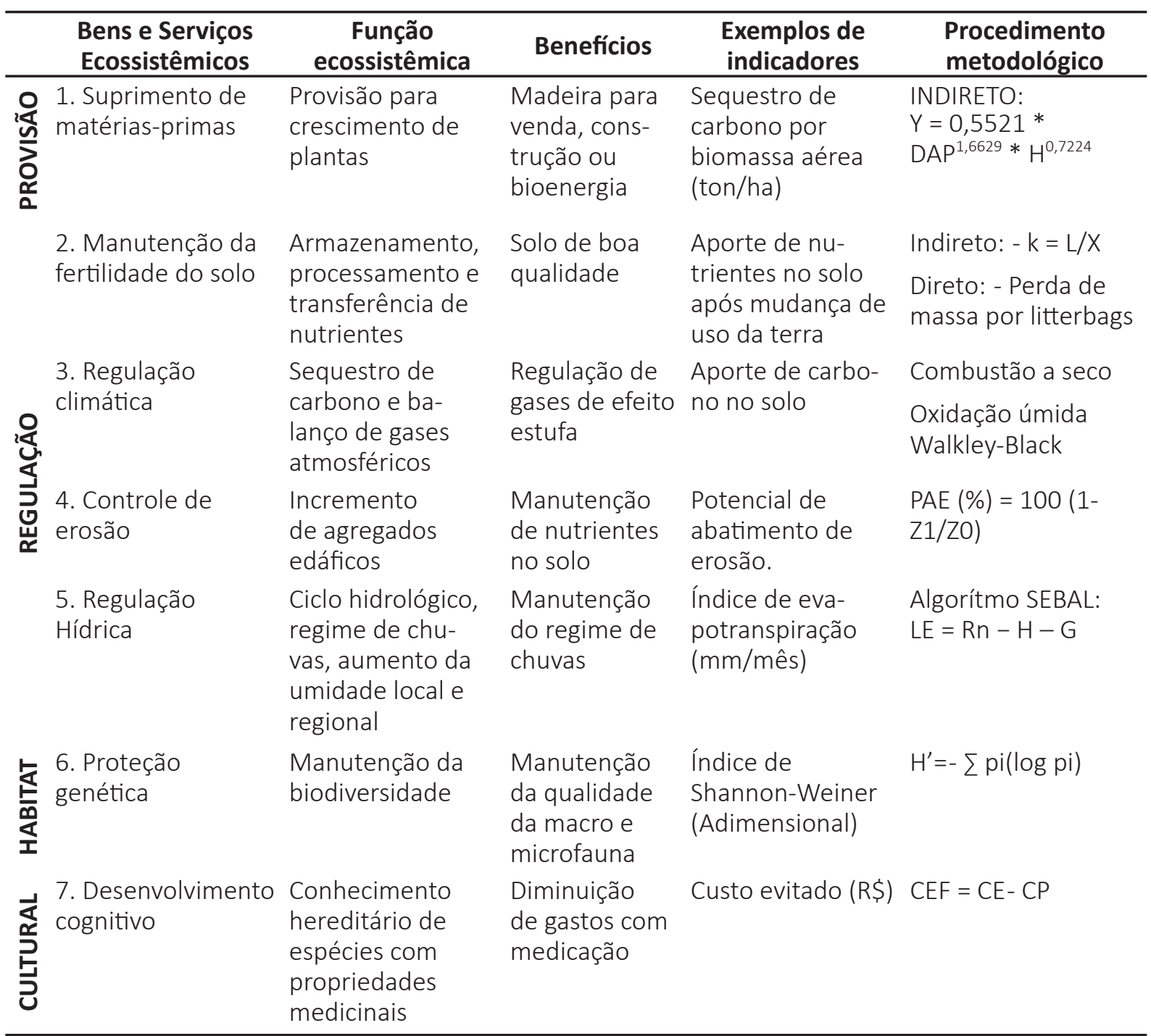

Fonte: Agência Nacional de Águas (ANA, 2012); Bezerra, Silva e Ferreira (2008); Bolfe e Batistella (2011); Motta (1997) (adaptado); Parron et al. (2015); Silva (2007); Soares e Froufe (2015). 
Contudo, para que sistemas agroflorestais produzam esse serviço ecossistêmico em quantidades adequadas para sua própria sustentação, é necessário o devido planejamento quanto às espécies a serem utilizadas, apropriadas ao clima local e com alta densidade e diversidade de plantas. É importante que a interpretação dos resultados do indicador leve em consideração as características genéticas das espécies e a idade, tanto dos indivíduos arbóreos como do sistema em si, de forma a apontar com maior exatidão oportunidades de melhoramento (CAMPELLO; FRANCO; FARIA, 2005).

Outra variável relacionada à prestação de SE pelo solo, desta vez incluindo o contexto das mudanças climáticas, por ser um dos sumidouros do carbono atmosférico, é o carbono orgânico (CO) no solo, o qual está presente em diferentes profundidades do solo, contribuindo assim para sua fertilidade. A verificação de CO no solo como componente na prestação de serviços ambientais ainda é tímida e pode ser incentivada, haja vista a existência de modelos de mudanças da matéria orgânica do solo (MOS) ao longo do tempo e, inclusive, o cálculo de seu estoque já reconhecido em programas de pagamentos por serviços ambientais (POWLSON; WHITMORE; GOULDING, 2011; PARRON; RACHWAL; MAIA, 2015).

Já o uso da biomassa arbórea como indicador de carbono (C) estocado poderia mensurar dois tipos de SE ao mesmo tempo. A princípio, o potencial serviço de regulação climática, a julgar pelo sequestro de carbono atmosférico e sua posterior não emissão, haja vista a "certeza" de que a exploração ocorreria com pelo menos 15 anos de crescimento dos indivíduos - tempo mínimo que o carbono deve ser estocado em biomassa vegetal para ser efetivamente considerado sequestrado. Como as espécies arbóreas são utilizadas em SAFs para recriar interações biofísicas de ambientes naturais, com o intuito de futura exploração madeireira, acaba-se por gerar o serviço de provisão de matéria prima para fins econômicos, outro tipo de SE.

Com base em dados levantados com uso do indicador, duas aplicações podem ser realizadas. A primeira é a comercialização de créditos de carbono em mercados internacionais voltados às mudanças climáticas, e a segunda é a avaliação dos indivíduos quanto ao tempo certo para exploração. Em virtude de o mercado ser estabelecido, acessível, com leis claras, da alta demanda e da facilidade de comercialização, ainda é mais vantajoso para proprietários optarem pela segunda alternativa.

Devido ao porte do segmento arbóreo, dos custos associados à retirada do indivíduo inteiro da terra e dos impactos causados por tal retirada, os métodos diretos de mensuração de carbono estocado em biomassa arbórea costumam ser inviáveis na maioria dos casos, restando ser aplicados quando se extraem poucos indivíduos ou nas etapas finais da exploração madeireira, onde o corte das árvores já faz parte do processo. Dessa forma, os dados da pesquisa poderiam ser obtidos após a etapa de corte da planta no processo produtivo.

No caso de SAFs, caso similar pode ser realizado com aquisição de dados após o corte dos indivíduos a serem comercializados. Para ambas as situações, a posse dessas informações pode ser aproveitada para a formulação de equações alométricas a fim de utilizá-las no planejamento do próximo ciclo de crescimento das espécies que serão exploradas.

Dentre os indicadores propostos, o potencial de abatimento de erosão se baseia na metodologia mais estabelecida no ramo científico para estudo de solos, a Equação Universal da Perda de Solo. Mesmo que a utilização de somente duas variáveis dessa equação para o cálculo do potencial de abatimento possa causar desconfiança, a decisão é respaldada e a favor da diminuição de custos durante a coleta. Dessa forma, com a definição do potencial de abatimento de 
erosão, preenche-se uma lacuna nos programas de incentivo à conservação, pois trata-se de um dos serviços ecossistêmicos mais contemplados em programas governamentais mundialmente.

Quando comparados entre diferentes modelos de SAFs, a prestação de SEs pode ser diferenciada. A partir de análises qualitativas de estudos e resultados de trabalhos como os realizados por Froufe e Seoane (2011), Torres et al. (2014), Torres (2015) e Velasques, Jacobi e Cardoso (2015), é possível estimar o potencial de geração dos serviços ecossistêmicos apresentados neste trabalho. O Quadro 1 apresenta essas potencialidades expressas de forma qualitativa.

O Quadro 1 elenca o potencial de prestação dos serviços ecossistêmicos selecionados neste trabalho. A variação desse potencial foi determinada a partir da densidade de indivíduos arbóreos presentes no SAF e seu arranjo espacial.

Conforme visto no Quadro 1, o sistema multiestratificado seria aquele com maior potencial de prestação de SEs, pois sua organização tenta recriar um ambiente natural de floresta secundária. Tanto a biomassa aérea como evapotranspiração, aporte de carbono e biodiversidadesão elevados por causa da sua densidade/ha de espécies arbóreas, cobrindo toda a extensão do SAF uniformemente. Devido a essa mesma uniformidade com que esses indivíduos são encontrados, caso o SAF se encontre em áreas ciliares, tem-se a redução da erosão, haja vista que o sistema radicular e copas das árvores permeariam profundamente toda a área com risco de erosão. 0 aporte de nutrientes, apesar de ser elevado, posteriormente apresenta alta competição entre as espécies lenhosas, resultando num balanço mediano de prestação desse SE. Nota-se que, no aporte de carbono, apesar de possuir a mesma competição nesse tipo de SAF, esse elemento é encontrado em camadas mais profundas do solo, sendo mais bem distribuído, enquanto que os nutrientes têm muita dependência da geração de serrapilheira, a primeira camada do solo, para tornarem os solos férteis em florestais tropicais (LEITÃO FILHO, 1987).

\begin{tabular}{|lcccc|}
\hline \multicolumn{1}{|c}{ Serviço ecossistêmico } & \multicolumn{4}{c|}{ Modelo de sistema agroflorestal } \\
& Multiestrato & Cultivo em aleias & Taungya & Cercas vivas \\
\hline Biomassa aérea & +++ & +++ & ++ & ++ \\
Aporte de nutrientes no solo & ++ & ++ & + & + \\
Aporte de carbono no solo & +++ & ++ & ++ & + \\
Abatimento de erosão & +++ & ++ & ++ & ++ \\
Evapotranspiração & +++ & ++ & ++ & + \\
Biodiversidade & +++ & +++ & ++ & + \\
Custo evitado com medicamentos & $=$ & $=$ & $=$ & $=$ \\
\hline
\end{tabular}

Quadro 1- Prestação de SE por modelo de SAF através dos indicadores selecionados

Legenda: (+): baixa prestação de SE; (++): prestação mediana de SE; e (+++): elevada prestação de SE; (=): prestação variável dependendo de fatores externos.

Cultivos em aleias, dependendo de sua organização, podem apresentar o mesmo número de indivíduos arbóreos que sistemas multiestratificados, mas organizados em "linhas", garantindo assim uma elevada biomassa/ha e biodiversidade. Contudo, devido ao distanciamento entre as aleias desses indivíduos umas das outras, a prestação dos outros SEs fica comprometida. Quanto ao aporte de nutrientes e carbono, por exemplo, mesmo que possa ser na mesma quantidade dos multiestratificados, este será disponibilizado somente para as aleias de cultivo próximas devido 
a sua distribuição espacial; em sistemas onde são encontradas mais de duas aleias de culturas anuais entre as espécies arbóreas, a prestação desses SEs fica comprometida.

O abatimento de erosão dependerá da largura total das aleias destinadas às espécies arbóreas presentes nas áreas ciliares. A mensuração de evapotranspiração utilizando métodos de sensoriamento remoto, por fim, é afetada na medida em que a refletância das aleias das culturas anuais, antes cobertas pelo dossel das árvores, compete por espaço no pixel da imagem com aquela proveniente dos indivíduos arbóreos, podendo alterar seus resultados (RAO; NAIR; ONG, 1997).

Sistemas taungya apresentam como grande diferencial o fato de as espécies arbóreas serem plantadas somente após a exploração das anuais, interferindo diretamente na prestação de SEs. A biomassa aérea, aporte de carbono, abatimento de erosão, evapotranspiração e biodiversidade só não são considerados elevados em virtude justamente desse intervalo em que a área é destinada exclusivamente para cultivos anuais, cabendo ressaltar que, quanto maior for esse tempo, menor será a prestação de SEs, analisando-se a longo prazo. O aporte de nutrientes, por sua vez, é considerado baixo por causa da necessidade de adubação no primeiro estágio de cultivo anual, nutrientes esses que são aproveitados na fase de instalação das espécies arbóreas.

SAFs em que as espécies arbóreas apresentam a função de cercas-vivas apresentam as mesmas problemáticas vistas nos sistemas de aleias, mas de modo mais elevado, haja vista que tais indivíduos são posicionados somente nos limites da área ou da propriedade, tendo pouca ou nenhuma influência ambiental sobre as espécies de cultivo devido ao distanciamento. Dessa forma, somente a biomassa aérea e abatimento de erosão podem apresentar potencial de prestação mediano dependendo da largura das faixas arbóreas e sua densidade. Cabe ressaltar que, caso parte dessas faixas sejam utilizadas para recobrimento de Áreas de Preservação Permanente (APP) curtas (10 a 30 metros) de recursos hídricos, o abatimento de erosão seria máximo, pois as árvores exerceriam o seu papel previsto no Código Florestal (RODRIGUES et al., 2007).

Em relação à prestação de serviços culturais, estes devem ser debatidos à parte, haja vista que dependem de fatores não só bióticos e estruturais de um SAF. Sua prestação depende primeiramente do quanto a comunidade ou proprietário em questão apresentam de conhecimento (normalmente tradicional) adquirido a respeito dos benefícios de determinadas espécies para a saúde e seu interesse em manejá-las, tendo ciência de que podem trazer menos benefícios econômicos quando comparadas com outras espécies frutíferas e/ou madeireiras. Não há também relação com o modelo de agroecossistema adotado, considerando-se que essas espécies, muitas vezes herbáceas, podem ser plantadas em espaços reduzidos fora do SAF.

\section{RELEVÂNCIA, POTENCIALIDADES E ENTRAVES PARA ADOÇÃO DE INDICADORES}

É usual encontrar na literatura científica indicadores e índices propostos para políticas públicas. Apesar de serem mensurados com certa facilidade, retratam a realidade somente de forma qualitativa ou com dados quantitativos para grandes áreas, reduzindo a um mesmo fator comum diferentes variáveis mais complexas, como vistos em Deponti, Eckert e Azambuja (2002). Outros exemplos desses tipos de análises podem ser a avaliação qualitativa de presença de estação de tratamento de efluentes numa cidade ou bairro e, quantitativa, o número hectares desmatados durante um ano na Amazônia. Mesmo que seja inegável a sua contribuição para a tomada de decisão, os indicadores servem somente como um ponto de partida para o aprofundamento nas 
questões socioeconômicas e ambientais a nível local, algumas vezes sendo propostos no ramo científico sem a devida explanação sobre o método de mensuração das variáveis, conforme visto em Pereira, Sauer e Fagundes (2016). A utilização de indicadores quantitativos com dados amostrais que representem esse nível de informação poderia, no primeiro exemplo citado, demonstrar os pontos com falha no tratamento de efluentes e seus motivos; e, no segundo exemplo, as causas, responsáveis e qualidade do ambiente após os desmatamentos.

Em termos de SE, é comum que estudos realizem uma homogeneização da prestação de determinados serviços por grandes áreas com características ambientais similares, tipos de vegetação ou biomas a partir de dados secundários, conforme apresentado por Cheng et al. (2011) ao estimar a pegada de carbono da agricultura para toda a China. Como o conhecimento sobre SE ainda pode ser considerado inicial, com grandes lacunas a serem preenchidas, e dependerem intrinsecamente de outros serviços, macroindicadores podem mascarar ainda mais a complexidade e real qualidade da sua prestação.

Indicadores ambientais com coleta de dados in loco, como os propostos neste trabalho, apresentam resultados que melhor refletem as variáveis presentes no ambiente. Sistemas agroflorestais dependem ainda mais desses tipos de indicadores, devido a sua maior sensibilidade aos fatores locais, resultando em prestação de diferentes quantidades de SE dependendo do desenho do SAF, mesmo que para as mesmas espécies utilizadas.

No caso de aplicação dos indicadores como suporte à decisão, não deixa de ser necessária uma avaliação com especialistas a fim de adaptar ou validar as metodologias propostas e definirem em consenso outros procedimentos que possam se adequar numa avaliação de $\mathrm{SE}$ em sistemas agroflorestais. Cabe ressaltar que a aplicação desses indicadores deve integrar ainda, dentre outros aspectos, a delimitação geográfica da avaliação dos SE, a escala temporal e determinação de outras características do sistema produtivo, conforme destacado por Deponti, Eckert e Azambuja (2002).

A utilização dos indicadores propostos neste estudo deve ser uma etapa intermediária no processo de planejamento da sustentabilidade dos SAFs. Ações seguintes podem envolver incentivos à alteração de técnicas por outras com maior prestação de serviços ecossistêmicos, mapeamento dos SAFs bem-sucedidos, sua replicação em outras propriedades e implantação de programas de pagamento por serviços ambientais.

\section{CONSIDERAÇÕES FINAIS}

A adoção de indicadores de SE em sistemas agroflorestais é implementada primeiro com o intuito de confirmar a prestação desses serviços, avaliar a indução de impactos ambientais positivos ao meio ambiente quando comparado com cultivos tradicionais e, após essas informações levantadas, como suporte à tomada de decisão. Utilizando-se dos princípios básicos que um indicador estratégico deve possuir, foi selecionado um total de cinco indicadores de serviços ecossistêmicos em SAFs, contemplando características como relevância, de fácil entendimento, capazes de refletir tendências temporais, cientificamente robustos e politicamente relevantes.

Mesmo que alguns possam não apresentar baixo custo (um dos princípios de indicadores de sustentabilidade), a exemplo da análise de serrapilheira e equação geral dos solos para estimativa de abatimento de erosão, as suas escolhas se justificam frente às suas eficiências comprovadas no meio científico e, por necessitarem de amostragem in loco, apresentação de 
maior capacidade de refletir os aspectos ambientais analisados. Outros indicadores, como a biomassa vegetal aérea, apresentaram a seleção da metodologia mais acessível dentre aquelas discutidas em pesquisas.

Com os indicadores descritos e relacionados com a potencial prestação de serviços ecossistêmicos, foi possível compará-los com os tipos de SAFs selecionados neste estudo, os modelos multiestrato, cultivo em aleias, taungya, e cercas vivas. O sistema multiestrato foi destacado como sendo aquele com o maior potencial de prestação de SEs, devido a sua similaridade com um ambiente natural de floresta secundária. O SAF do tipo cultivo em aleias, poderiam também oferecer SEs relacionados com a proteção do habitat e o suprimento de matérias primas, desde que a organização de seus indivíduos arbóreos favorecesse uma elevada quantidade de biomassa e de biodiversidade por hectare. Outros serviços, tais como aporte de carbono no solo, abatimento de erosão e evapotranspiração nos SAFs cultivados em aleias, teriam um potencial menor que quando oferecidos nos sistemas em multiestrato.

Os sistemas taungya e cercas vivas foram identificados como tendo um menor potencial para prestação de SEs considerando os indicadores utilizados neste estudo, devido a sua configuração, função e forma de exploração. No entanto, quando se trata do objetivo específico de recobrimento de áreas de preservação permanente (APPs) de recursos hídricos, o SE abatimento de erosão se destaca nos SAFs do tipo cerca vivas.

Em nível de políticas públicas, a utilização de indicadores para avaliação dos serviços ecossistêmicos provenientes de SAFs em uma mesma região (p. ex. bacia hidrográfica) permite visualizar quais recursos naturais estão sendo mais impactados e se há discrepância na prestação de um mesmo SE dentro da área total. Caso esse segundo ponto seja identificado, uma análise entre as diferentes técnicas empregadas nos SAFs permite distinguir aquelas com maior prestação de SE.

\section{REFERÊNCIAS}

AGÊNCIA NACIONAL DE ÁGUAS (ANA) (Brasil). Programa Produtor de Água: manual operativo. Brasília: ANA, 2012. 74p.

ALVES, T. S.; CAMPOS, L. L.; ELIAS NETO, N.; MATSUOKA, M.; LOUREIRO, M. F. Biomassa e atividade microbiana de solo sob vegetação nativa e diferentes sistemas de manejos. Acta Scientiarum Agronomy, Maringá, PR, v. 33, n. 2, p. 341-7, 2011.

ARCO-VERDE, M. F.; AMARO, G. C. Metodologia para análise da viabilidade financeira e valoração de serviços ambientais em sistemas agroflorestais. In: PARRON, L. M.; GARCIA, J. R.; OLIVEIRA, E. B.; BROWN, G. G.; PRADO, R. B. Serviços ambientais em sistemas agrícolas e florestais do bioma Mata Atlântica. Brasília, DF: Embrapa, 2015. Capítulo 30.

BEZERRA, B. G.; SILVA, B. B.; FERREIRA, N. J. Estimativa da evapotranspiração real diária utilizando-se imagens digitais TM-Landsat5. Revista Brasileira de Meteorologia, v. 23, n. 3, p. 305-17, 2008.

BOLFE, E. L.; BATISTELLA, M. Análise florística e estrutural de sistemas silviagrícolas em Tomé-Açu, Pará. Pesquisa Agropecuária Brasileira, v. 46, n. 10, p. 1139-47, 2011.

CAMPELLO, E. F. C.; FRANCO, A. A.; FARIA, S. M. Aspectos ecológicos da seleção de espécies para sistemas agroflorestais e recuperação de áreas degradadas. In: AQUINO, A. M.; ASSIS, R. L. (Ed.). Agroecologia: princípios e técnicas para uma agricultura orgânica sustentável. Brasília, DF: Embrapa, 2005. Capítulo 20.

CHENG, K.; PAN, G.; SMITH, P.; LUO, T.; LI, L.; ZHENG, J.; ZHANG, X.; HAN, X.; YAN, M. Carbon footprint of China's crop production- An estimation using agro-statistics data over 1993-2007. Agriculture, Ecosystems and Environment, v. 142, n. 3-4, p. 231-7, ago. 2011. 
DEPONTI, C. M.; ECKERT, C.; AZAMBUJA, J. L. B. Estratégia para construção de indicadores para avaliação da sustentabilidade e monitoramento de sistemas. Agroecologia e Desenvolvimento Rural Sustentável, v. 3, n. 4, 2002.

FERRAZ, J. M. G. As dimensões da sustentabilidade e seus indicadores. In: MARQUES, J. F.; SKORUPA, L. A.; FERRAZ, J. M. G. (Ed.) Indicadores de sustentabilidade em agroecossistemas. Jaguariúna, SP: Embrapa, 2003.

FISHER, B.; TURNER, R. K.; MORLING, P. Defining and classifying ecosystem services for decision making. Ecological Economics, v. 68, n. 3, p. 643-53, 2009. Disponível em: <http://www.sciencedirect.com/science/ article/pii/S0921800908004424>. Acesso em: 21 out. 2012.

FLICK, U. Introdução à pesquisa qualitativa. Porto Alegre: Artmed, 2009.

FROUFE, L. C. M.; SEOANE, C. E. S. Levantamento fitossociológico comparativo entre sistema agroflorestal multiestrato e capoeiras como ferramenta para execução de reserva legal. Pesquisa Florestal Brasileira, v. 31, n. 67, 2011.

IDOL, T.; HAGGAR, J.; COX, L. Ecosystem services from smallholder forestry and agroforestry in the tropics. In: CAMPBELL, W. B.; ORTÍZ, S. L. Integrating agriculture, conservation and ecotourism: examples from the field. Nova York: Springer, 2011.

LEITÃO FILHO, H. F. Considerações sobre a florística de florestas tropicais e sub-tropicais do Brasil. Instituto de Pesquisas e Estudos Florestais, n. 35, p. 41-6, 1987.

MILLENNIUM ECOSYSTEM ASSESSMENT (MEA). Ecosystems and human well-being: current state and trends. Washington: Island Press, 2005. v. 1Disponível em: <http://www.millenniumassessment.org/ documents/document.766.aspx.pdf>. Acesso em: 5 abr. 2016.

MOTTA, R. S. Manual para valoração econômica de recursos ambientais. Rio de Janeiro: Instituto de Pesquisa Econômica Aplicada, 1997.

NAIR, P. K. R. An introduction to agroforestry. Dordrecht, Holanda: Kluwer Academic Publishers, 1993.

PALUDO, R.; COSTABEBER, J. A. Sistemas agroflorestais como estratégia de desenvolvimento rural em diferentes biomas brasileiros. Revista Brasileira de Agroecologia, v. 7, n. 2, p. 63-76, 2012.

PARRON, L. M.; RACHWAL, M. F. G.; MAIA, C. M. B. F. Estoques de carbono no solo como indicador de serviços ambientais. In: PARRON, L. M.; GARCIA, J. R.; OLIVEIRA, E. B.; BROWN, G. G.; PRADO, R. B. Serviços ambientais em sistemas agrícolas e florestais do bioma Mata Atlântica. Brasília, DF: Embrapa, 2015. Capítulo 7.

PEREIRA, M. S.; SAUER, L.; FAGUNDES, M. B. B. Mensurando a sustentabilidade ambiental: uma proposta de índice para o Mato Grosso do Sul. Interações, v. 17, n. 2, p. 327-38, abr./jun. 2016.

POWLSON, D. S.; WHITMORE, A. P.; GOULDING, K. W. T. Soil carbon sequestration to mitigate climate change: A critical re-examination to identify the true and the false. European Journal of Soil Science, $\mathrm{v}$. 62, n. 1, p. 42-55, 2011.

RAO, M. R.; NAIR, P. K. R.; ONG, C. K. Biophysical interactions in tropical agroforestry systems. Agroforestry Systems, v. 38, n. 1, 1997.

RODRIGUES, E. R.; CULLEN JR, L.; BELTRAME, T. P.; MOSCOGLIATO, A. V.; SILVA, I. C. Avaliação econômica de sistemas agroflorestais implantados para recuperação de reserva legal no Pontal do Paranapanema, São Paulo. Revista Árvore, v. 31, n. 5, 2007.

SAMPIERI, R. H.; COLLADO, C. F.; LUCIO, P. B. Metodología de la investigación. México, DF: McGraw-Hill Educación, 2014.

SILVA, R. R. Alometria, estoque e dinâmica da biomassa de florestas primárias e secundárias na região de Manaus (AM). 2007. 152f. Tese (Doutorado em Ciências de Florestas Tropicais)- Instituto Nacional de Pesquisas da Amazônia, Universidade Federal do Amazonas (UFAM), Manaus, 2007. 
SOARES, M. T. S.; FROUFE, L. C. M. Estimativa de ciclagem de nutrientes em ecossistemas florestais por meio da produção e decomposição de serrapilheira. In: PARRON, L. M.; GARCIA, J. R.; OLIVEIRA, E. B.; BROWN, G. G.; PRADO, R. B. Serviços ambientais em sistemas agrícolas e florestais do bioma Mata Atlântica. Brasília, DF: Embrapa, 2015. Capítulo 11.

TEEB FOUNDATIONS. The economics of ecosystems and biodiversity: ecological and economic foundations. Londres: Earthscan, 2010.

TORRES, C. M. M. E.; JACOVINE, L. A. G.; OLIVEIRA NETO, S. N.; ALVES, E. B. B. M. Sistemas agroflorestais no Brasil: uma abordagem sobre a estocagem de carbono. Pesquisa Florestal Brasileira, v. 34, n. 79, p. 235-44, 2014.

TORRES, C. M. M. E. Estocagem de carbono e inventário de gases de efeito estufa em sistemas agroflorestais, em Viçosa, MG. 2015. 97f. Tese (Doutorado em Ciências Florestais) - Universidade Federal de Viçosa (UFV), Viçosa, MG, 2015.

VELASQUES, N. C.; JACOBI, U. S.; CARDOSO, J. H. Espécies nativas e naturalizadas utilizadas em consórcios para formação de cercas vivas. Revista Brasileira de Agroecologia, v. 10, n.1, p. 3-11, 2015.

WODA, C. Indicadores para serviços ambientais em sistemas agroflorestais: um estudo de caso no nordeste paraense. In: PORRO, R. (Ed.). Alternativa agroflorestal na Amazônia em transformação. Brasília, DF: Embrapa, 2009.

\section{Sobre os autores:}

Renan Coelho de Vasconcellos: Mestre em Ciências Ambientais. E-mail: renanrcv@gmail.com Norma Ely Santos Beltrão: Doutora em Economia Agrícola. E-mail: normaelybeltrao@gmail.com 